\title{
Psychological Reality of Chunks for EFL Chinese Students -Evidence from Speaking Fluency
}

\author{
Miao Haiyan ${ }^{1, *}$ \\ ${ }^{1}$ School of Foreign Languages, Jiangxi Normal University, Nanchang, China \\ *Correspondence: School of Foreign Languages, Yaohu Campus, Jiangxi Normal University, Nanchang, 330022, \\ China. Tel: 1-508-8-067-253. E-mail: salomehy@aliyun.com
}

Received: November 20, 2014

Accepted: December 3, 2014 Online Published: December 15, 2014

doi:10.5430/wje.v4n6p101

URL: http://dx.doi.org/10.5430/wje.v4n6p101

\begin{abstract}
The study explores the psychological reality of chunks for EFL Chinese students. Speech samples from three various proficiency groups are examined with the help of the computer program Cool Edit 2.0, and speaking fluency is thus determined. It is found out that speaking fluency is not linear, and fluent subjects can use, store and retrieve chunks of sentence builders as one single unit while non-fluent ones cannot, which can be attested by the fact that fluent subjects do not or seldom pause frequently within chunks of sentence builders and thus not break them up. These findings suggest that chunks are psychologically real for Chinese EFL students, and chunks should be combined into EFL learning and teaching in China.
\end{abstract}

Keywords: chunks; sentence builders; fluency

\section{Introduction}

Fluency together with lexical learning has been of much interest to researchers, teachers and learners as well. Recent studies have included the analysis of chunks (and especially chunks of sentence builders) in the study of second language speech (c.f. Korsmos \& Denes, 2004). However, both chunks and fluency are research areas that need to be further explored. This paper is thus dedicated to the study of the correlation between the use of chunks of sentence builders and fluency.

\section{Literature Review}

\subsection{Importance of Chunks}

Since the mid 1950s, the linguistic theory has been dominated by Chomsky's view of language, with TG grammar being the central. The majority of SLA studies are so motivated that it is held that adult language as well as learner language is mainly a system of generative rules. Despite Chomsky's sweeping influence, there have always been linguists who have pointed out that "ready-made chunks of unanalyzed language are as important as productive rules" (Weinert 1995). Researchers have identified 4 types of four types of chunks: collocations, idioms, fixed phrases (which include items like of course, at least, as well as greetings and phatics and proverbs) and sentence builders (see Nattinger \& DeCarrico, 1992). Collocations are fixed, but most of them are compositional. Idioms are characteristic of their high non-compositionality. Fixed phrases are highly fixed, but their compositionality is variable in kind and degree. Sentence builders are only partly fixed, and their surface meanings can be readily decoded. But there also exists non-compositionality in sentence builders, which stems from their discoursal uses.

In recent years, the role of chunks has been highlighted by many scholars and researchers, because possibly as much as $70 \%$ of the adult native language may be chunks (c.f. Wray \& Perkins, 2000), and much of lexis consists of sequences of words operating as single units (Schmitt, 2000). Chunks are pre-fabricated language that can be stored, retrieved and used as a whole without the need to compose them on-line through much consideration of word choice and grammar. This means that they can ease the on-line language processing load so that language fluency can be greatly enhanced. Besides, one of the reasons why chunks are so common in language is that they are often typically related to functional language use, such as apologizing, making requests and commands. Then the ability to use 
chunks can contribute to the appropriateness and idiomaticity of language use as well. The importance of chunks has been attracting the attention of both the linguistic and psycholinguistic circles. It is also found that chunks are processed more quickly than non-chunks by native and nonnative L2 speakers (Conklin \& Schmitt, 2008). Chunks are also important in English lingua franca communication, because the use of chunks indicate a language use mode of common pragmatic, discourse and grammatical features (Kesches, 2010).

\subsection{Importance of Fluency in Oral Production}

It is true that fluency can be used to describe written and reading performance (Lennon, 1990), but it is mainly restricted to oral production. Though not precisely defined yet, fluency is a popular term among students, teachers and researchers for its importance in language learning and teaching. In fact, the importance of fluency can be well manifested by the fact that the overall goal of second or foreign language learners may be to produce fluent speech. Although fluency is usually taken as the ultimate goal of foreign language learning (Kormos \& Denes, 2004), many Chinese EFL students still cannot communicate in English after years of learning (Wang, 2010)

\subsection{Research Questions}

From the above literature review, it can be seen that fluency is one of the most important element in Chinese EFL students' foreign language development, and theoretically chunks can well facilitate the development of speaking fluency. However, the psychological reality of chunks still remains unanswered for Chinese EFL students. We will focus on one type of chunks, namely chunks of sentence builders. Our research questions are:

First, do Chinese EFL students treat chunks as wholes, so their speaking fluency is facilitated?

Second, to what degree do students at various proficiency levels use chunks?

\section{Method}

\subsection{Subjects}

In order to find out whether there exists a correlation between the use of chunks of sentence builders and the development of fluency, the fluency proficiency/level has to be decided in the first place, then the use of chunks of sentence builders is analyzed and psychological reality can be decided. In order to achieve all this, three distinct groups of learners were chosen: newly enrolled English major freshmen, English majors that had just passed TEM4, and English majors that had passed TEM8. Each group consisted of 10 participants, and there would be 30 participants all together. Then from each group, the least and most fluent subjects from each group are selected, so that the psychological reality of chunks can be studied in detail in fluency level and proficiency level.

\subsection{Prompt}

As for the trigger used to promote speaking, a letter from $21^{s t}$ Century (Issue No. 557.) was chosen. The letter was written by a Chinese college student who had problems getting along with his friend, and he wrote the letter to ask for suggestions. The reason why this letter was chosen was that the problem encountered by this student was quite common among Chinese college students and so the participants at least would not feel that they had nothing to say on such a familiar topic.

\subsection{Research Procedure}

The participants were given 2 minutes to prepare and then instructed to talk as much as possible. Their talks, which last about 2-3 minutes long on average, were recorded on a digital recorder and then transferred to the computer for further analysis.

\subsection{Data Analysis}

Then we would be more specific about the data analysis. After the sample collection, all the speech samples were transcribed. During the transcription, the author aimed for an accurate reproduction of the speech, including repetitions, hesitations and pauses, thus allowing a comparatively more accurate analysis of fluency in terms of both an oral productive process and temporal phenomenon. In addition, the author added some conventional punctuation (full stop, comma and question mark) in a way conventionalized for the written representation of speech. And then the analyzer Cool Edit 2.0 was used in order to detect pauses of 0.3 seconds or above, which is vital to the study of fluency. 


\section{Results}

\subsection{Speaking Fluency}

Speaking fluency is defined in terms of five temporal variables (Towell et al., 1996): speaking rate, articulation rate, mean length of run (MLR), phonation time ratio (PTR) and average length of pause (ALP).

The trendline of the mean value of these five temporal variables is presented in Figure 1.

For speaking rate, it seems that on the global measure, group 2 (TEM4-passers) is the most fluent, group 3 (TEM8-passers) less fluent and group 1 (newly-enrolled freshmen) the least. To be more specific, the average SR increases between group 1 and group 2, group 1 and group 3 are from 101.29 to 143.03 syllables (41.21 per cent) and from 101.29 to 139.60 per minute (37.82 per cent) respectively. For articulation rate, group 2 is able to utter the most syllables per second during the time spent speaking, and accordingly group 3 less and group 1 the least.

In terms of MLR, the results have yielded an average of 5.18 syllables for group 1, 6.49 syllables for group 2 and 6.64 syllables for group 3. There is a difference of 25.29 per cent between group 1 and group 2, 28.19 per cent between group 1 and group 3 , and 2.31 per cent between group 2 and group 3.

Turning now to the experimental evidence on PTR, we find that there is an increase in the mean value, which might suggest that subjects at a higher proficiency level tend to spend more time in speaking compared to the total time. The increases are 23 per cent (group 2 over group 1), 25.07 per cent (group 3 over group 1) and 1.7 per cent (group 3 over group 1). There is a difference of 25.29 per cent between group 1 and group 2, 28.19 per cent between group 1 and group 3, and 2.31 per cent between group 2 and group 3 .

Results show that there remains a decrease in the average length of pause, which means that students at higher proficiency levels are likely to spend less time pausing in average. The decreases are 78.21 per cent (between group 1 and group 2), 85.33 per cent (between group 1 and group 3) and 4 per cent (between group 2 and group 3).

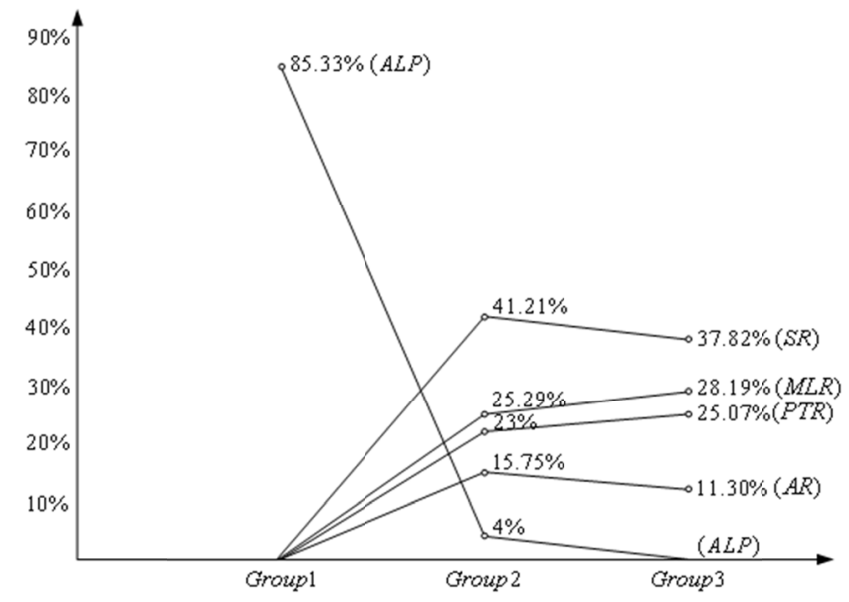

Figure 1. Trendlines of Increases/Decreases of the Five Temporal Variables

\subsection{Proceduralization of Chunks of Sentence Builders}

Then how do these proficiency groups with different speaking fluency use chunks of sentence builders? Are chunks of sentence builders psychologically real? We still have to make sure whether the subjects do spend less time in retrieving chunks of sentence builders than other elements of language use, which in other words means that the learners have proceduralized them as one single unit, and they will store and use these chunks of sentence builders as a whole accordingly. Solid evidence of all this is that the learners will not pause within the chunks of sentence builders. By not pausing, we mean that the learners will not pause for 0.3 seconds or above within the chunks of sentence builders. Therefore analyses will be carried out to see whether the sentence builders are stored and retrieved as a whole in language use through the exploration of the pausing patterns by these three groups of learners. As for the subjects to be studied in more detail, both the least fluent and most fluent ones in each group are chosen, because they are representative of fluent and non-fluent subjects at various proficiency levels.

\subsubsection{Least Advanced Learners with the Highest and Lowest Levels of Fluency}

The following extracts are from the recordings of the subjects' monologues. The extracts are selected to our purpose, as they are those runs that include sentence builders and some surrounding ones. The information presented in the transcription is as follows: a bold-print number such as -1- numbers the run for ease of reference. Figures between () 
represent first the time taken to produce the preceding run (.95 $\quad$ ) for example, and second the number of syllables in that run ( 3 ). Figures in the square brackets [.30] refer to pause time expressed in seconds. All the unfilled pause of .30 seconds or above are recorded and they define the end of the run.

We'd like to begin first with the analyses of least advanced learners (newly enrolled English majors freshmen) who show the highest and lowest levels of fluency respectively:

(1) -1- So I think (.95 3$)$ [.30] -2- I think it's usual for new students in $(2.42 \quad 10)$ [.39] -3- er in the university that $(1.83$; 9) [.43] -4- that she or he communicate with his classmates. ... and -22- maybe there is no contact with each other, but you will you will keep your friends in your heart (5.83 22) [.37] -23- er in the in the deep heart (2.07 7) [.63] -24- so em (.99 1 2) [.41] -25- so I think (.80 3) [.49] -26- er... -36- I think I I can cite something from en (2.9 10$)$ [2.28]... -52- I think he will lost (1.54 5$)$ [.36] -53- the (.15: 1) [.47] -54- he will lose the friendship (1.90: 6)

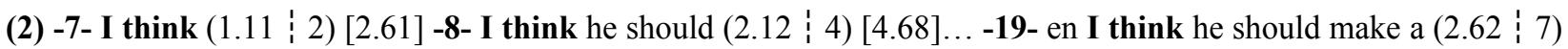

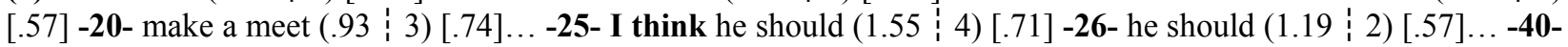
I think he (1.46 3 3) [1.95] -41- em (.70: 1 ) [3.01] -42- he should tell it to her (2.51 6 6) [2.22] .. -51- I think (1.22

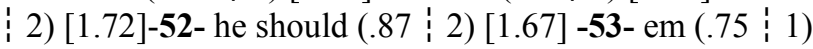

Text (1) is of subject 1 with the highest level of fluency in this group, while text (2) is that of subject 2 with the lowest level of fluency. Examining the texts in detail may allow us to suggest the following characteristics. First, subject 1 uses only one more sentence builder (7) than subject 2 (6). Second, these two subjects both seem to be very fond of one sentence builder, that is "I think...", which may serve as evidence that they know very limited sentence builders or have few sentence builders at their own disposal. Third, subject 1 seems to be more varied in using sentence builders than subject 2, as subject 2 uses exclusively "I think..." and subject 1 uses two more kinds "It is adj. (for sb.)...that" and "there be...". Finally, both the two subjects store and retrieve the sentence builders as one single unit, which can be seen from the places of pauses in the subjects' speech production. In the two texts, the sentence builders are not broken up by pauses frequently internal to themselves. Subject 1 is not consistently able to produce "It is adj. (for sb.)...that" as one unit, as both repetition of "that" and pausing of 1.83 seconds occurred after "that". This may be due to the fact that subject 1 still has problems in combining this sentence builder with other sentence elements. It needs to be pointed out that although subject 2 never pauses between "I" and "think" when using the sentence builder "I think", subject 2 pauses very frequently when combining the sentence builders with other sentence elements and using those elements as well, which is much less prominent in subject 1.

Therefore, for all the differences and similarities in using sentence builders, both subject 1 and subject 2 do not pause within the sentence builders themselves, although sometimes it may be difficult for them to combine the sentence builders with other sentence elements.

\subsubsection{Less Advanced Learners with the Highest and Lowest Levels of Fluency}

Then we come to the analyses of less advanced learners (group 2) with the highest and lowest levels of speaking fluency respectively, the texts of which are presented below.

(3) -1- well (.45 $\quad 1$ ) [1.66] -2- I think first of all I will em remind you to make clear what's on your mind (5.02 18$)$ [.58]... -7- excellent. I think these items are (2.39 9 9) [.96]... -13- so I think (.64:3) [.33] -14- well first of all it is very important to distinguish these two different (4.95 20) [.69] -15- feeling because they can (1.13 6$)$ [.37] -16- cause totally different result (2.19 9) [.44] -17- if you just like her as a good friend, then I think (3.40 12$)$

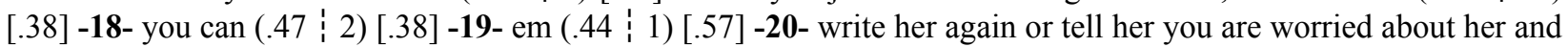
(4.22 15) [.30] -21- I think maybe she is now em busy with study or maybe she has a new friend (6.08 121$)$ [.46] -22- I think you do not have to worry if you just like her as a friend, because (4.09: 19) [.32] .. -26- I think you'd better (1.29 5) [.57] -27- er think about it deeply, because (2.29 9) [1.18] -28- em (.47 1$)$ [.33] -29- you are a little worried about her new friend, maybe you are thinking about that she got a boyfriend (6.14 26) [.59] -30- em

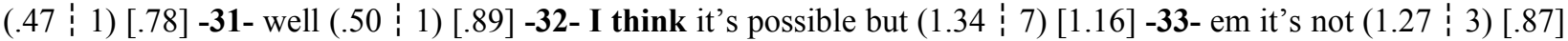
-34- two hundred percent, you could not sure, right? (2.39 10$)$ [.64] -35- so em (1.10 2$)$ [1.20] -36- I think (.40 2) [.65] -37- well that's my own opinion, personal opinion ... -44- if not, I think you can (1.49:6) [.77] -45- er ask her to (1.62 4) [.38] -46- be your girlfriend (1.15 4) [.45] -47- maybe this not a very good idea, but I think it's (2.68 14$)$ [.31] -48- a good idea to (1.74 5$)$ [.30] -49- em (.44: 1$)$ [.84] -50- really your girl is lovely (1.69 7$)$ [1.33] -51- em (.56: 1) [2.72] -52- I think (.47: 2) [1.05] -53- what (.45: 1) [.50] -54- I suggest you to do (1.22 6)

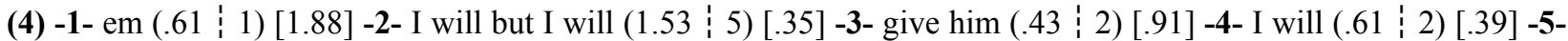


first I will ask ask my friend (2.50 $\quad 7)$ [.69] -6- em for help (.83 3 3) [.98] -7- em maybe some (1.07 4) [.45] -8some friend with $(.94 \quad 3)$ [.53] -9- with (.27 1$)$ [.33] -10- en such kind of experience. I will ask for for for his advice (4.35 16$)$ [.69] -11- em (.41 1 1) [2.41] -12- em (.41: 1$)$ [.32] -13- I think (.42: 2) [.76] -14- a give talk a talk heart to heart may (2.90 19$)$ [.44] -15- may well solve problem (1.72: 5$)$ [.57] -16- em (.67 1 1) [.75]

Text (3) is that of subject 1 in this group with the highest level of fluency, while text (4) is that of subject 2 with the lowest level of fluency. From the two texts, several points can be perceived. Firstly, subject 1 in this group uses much more sentence builders than subject 2. Subject 1 uses 14 sentence builders, including 12 "I think (that)...", 1 "It is adj. to..." and 1 "You'd better...", while subject 2 uses only 1 one sentence builder "I think...". So subject 1 uses more sentence builders than subject 2 not only in quantity but also in quality. However, it must also be admitted that both the two subjects depend too much on one single sentence builder "I think (that)...", as subject 1 in this group uses 12 such sentence builder of the total 14 and subject 2 uses only one sentence builder which is "I think (that)...". Secondly, both subject 1 and subject 2 in this group do not pause within the sentence builders themselves, which means that they pause either directly after "I think (that)" or after other syntactic elements introduced by the sentence builders. This pattern of pausing suggests that these subjects do store, retrieve and use the sentence builders as a single unit, which is also true of the subjects from group 1. Yet unlike those subjects in group 1, these two subjects in group 2 are much more polarized and also can consistently produce these sentence builders as one unit.

4.2.3 Advanced Learners with the Highest and Lowest Levels of Fluency

And finally, we come to the comparison of advanced learners with the highest and lowest levels of speaking fluency respectively in order to see whether students at this proficiency level can also store and retrieve chunks of sentence builders as one single unit and whether there is some difference between this group and the other two groups, which is given full expression to in the subjects' use of chunks of sentence builders.

(5) -1- em (.79: 1) [1.09] -2- her his problem is (1.23 5) [.36] -3- she doesn't contact (1.16 5) [.32] -4- she didn't contact with him (1.39: 7) [.81] -5- so (.61: 1) [.30] -6- an-and he wrote a letter to her $(2.07 \quad 9)$ [.65] -7- em my first suggestion would be she he probably should give her a phonecall (6.0: 19$)$ [.65] -8- because I think (.99 4) [.30] -9- everybody knows that phonecall is more direct than (3.36 14$)$ [.44] -10- than em writing letters (1.84 6$)$ [.58]... -15- he'd better go to Shanghai to meet her $(2.79$ 10) [1.22] .. -20- if the girl hasn't write her a letter for some reason, it must be that the girl is very busy or something has occupied her (7.53 33$)$ [.30]... -25- what I think is $(.93$ 4) [1.29] -26- em in no matter in what case (2.53 8) [.79] -32- em common among students, university students. I I think em especially when we were er freshmen (7.51 28) [.36] -33- em we usually have contact with many er former friends, but as (4.65 17) [.30] -34- er time goes, we lost contact for every one gets

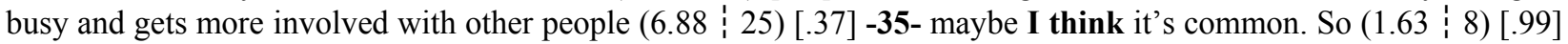
-36- em if this guy really cares about that girl and wants some kind of relationship between them (7.04: 23) [.69] -37- he really should do something more not just (3.29 10$)$ [.41] -38- thinking and complaining (1.94 6$)$ [1.00] -39- em (.61: 1) [2.93] -40- so it depends on what kind of relationship he wants with the girl (3.09: 17) [.49] -41em (.62: 1 ) [2.16] -42- maybe that's all (.71:4)

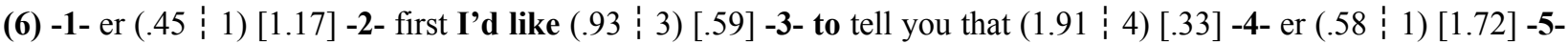

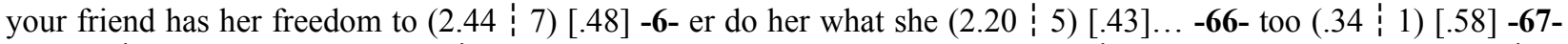
em (.68: 1) [1.47] -68- just (.59: 1) [.34] -69- er forget about it and then (1.96: 8$)$ [.52] -70- er I hope (1.17 3$)$ $\left[\begin{array}{ll}.73]-71-\text { you }(.31 & 1)[.37] \ldots\end{array}\right.$

Text (5) is that of advanced English learner 1 with the highest level of fluency, while text (6) is that of advanced English learner 2 with the lowest level of fluency. Examining the above two texts in detail allows us to suggest the following. First, subject 1 in this group uses more chunks of sentence builders than subject 2. Subject 1 uses 8 sentence builders while subject 2 uses only 2 . In addition, subject 1 is able to use sentence builders with more varied functions, for example, asserting "I think (that)...", giving suggestions "My first suggestion would be..." and "he'd better...", guessing "It must be that..." and qualifier "It depends on...". On the contrary, subject 2 only uses asserting "I hope..." and expressing likes "I'd like to...". Then generally speaking, both the two subjects do not pause within the sentence builders themselves, with the exception of subject 2 when using the sentence builder of "I'd like to...". Finally, one prominent characteristic is that subject 1 is more likely to pause after the syntactic elements or strings introduced by sentence builders, but not directly after the sentence builders themselves. This can be taken as the evidence that it is less laborious for subject 1 rather than other subjects to combine sentence builders with other sentence elements, which means less total pausing time and pausing more between boundaries rather than within the boundaries so that the speed demands are satisfied. 


\section{Conclusion}

Fluency results clearly show that newly-enrolled freshmen are the least fluent in terms of these five defining variables, while sophomores and seniors greatly improved their speaking fluency though with no obvious gains between. It may be that after two years of study in college, a shift in study focus may occur. In the last two years in college, students receive less training in language skills, but pay more attention to more scholarly courses such as linguistics, literature and translation theories. This shift of study focus may cause a plateau effect in the development of fluency, as is shown by our results.

Proceduralization analyses indicate that nearly all the learners at various proficiency levels can store and retrieve sentence builders as one single unit, which can be well attested by the fact that sentence builders are not broken up by pauses of 0.3 seconds or above. So it seems that the learners have already proceduralized the sentence builders in their mind. According to Gobet and Simon's (2002) template theory, the learners have then stored in LTM the sentence builders that contain slots to be filled with various types of information. If a certain function in speech is required or recognized, the sentence builders can be used, with modifications, to store the information and complete the whole sentences. In this way, less pausing will appear in speech and the speed demands can be met. This result approves the theoretical prediction among Chinese EFL students that the ability to use effectively more chunks of sentence builders can facilitate fluency.

Based on the above results, it is psychologically real for Chinese EFL students in terms of the use of chunks. It then follows that chunks of sentence builders should be presented as a whole in the process of learning and teaching of English. In this way, the students will tend to use, retrieve and store them as one single unit, thus reducing on-line processing time and improving fluency as well as accuracy. However, it should be noted that the development of speaking fluency is not linear for Chinese EFL students. It may be feasible for EFL teachers and students to bear in mind that practice and continuous input can enhance the development of speaking fluency as well as strengthen the psychological reality of chunks.

\section{References}

Conklin, K., \& N. Schmitt. (2008). Formulaic sequences: are they processed more quickly than nonformulaic language by native and nonnative speakers. Applied Linguistics, 29(1), 72-89. http://dx.doi.org/10.1093/applin/amm022

Gobet, F., \& S. Jackson. (2002). In search of templates. Cognitive Systems Research, 3(1), 35-44. http://dx.doi.org/10.1016/S1389-0417(01)00042-0

Kecskes, I. (2010). Formulaic language in English Lingua Franca. In Patrick Hanks and Rachel Giora (eds.), Metaphor and Figurative Language: Critical Concepts in Linguistics. Oxford/New York: Routledge. (reprint of 2007 paper).

Kormos, J., \& M. Denes. (2004). Exploring measures and perceptions of fluency in the speech of second language learners. System, 32(2), 145-164. http://dx.doi.org/10.1016/j.system.2004.01.001

Lennon, P. (1990). Investigating fluency in EFL: a quantitative approach. Language Learning, 40(3), 387-417. http://dx.doi.org/10.1111/j.1467-1770.1990.tb00669.x

Nattinger, J. R., \& J. S. DeCarrico. (1992). Lexical Phrases and Language Teaching. Oxford: Oxford University Press.

Schmitt, N. (2000). Key concepts in ELT. ELT Journal, 54(4), 400. http://dx.doi.org/10.1093/elt/54.4.400

Towell, R., R, Hawkins., \& N. Bazergui. (1996). The development of fluency in advanced learners of French. Applied Linguistics, 17(1), 84-119. http://dx.doi.org/10.1093/applin/17.1.84

Wang, C. (2010). How to learn a foreign language. Beijing: Foreign Language Teaching and Research Press.

Weinert, R. (1995). The role of formulaic language in second language acquisition: a review. Applied Linguistics, 16(2), 180-205. http://dx.doi.org/10.1093/applin/16.2.180

Wray, A., \& M. R. Perkins. (2000). The functions of formulaic language: an integrated model. Language \& Communication, 20(1), 1-28. http://dx.doi.org/10.1016/S0271-5309(99)00015-4 